\title{
Características físico-químicas de fontes proteicas e suas interações sobre a degradação ruminal e a taxa de passagem
}

\author{
Mário Adriano Ávila Queiroz ${ }^{1}$, Ivanete Susin², Alexandre Vaz Pires ${ }^{2}$, Evandro Maia Ferreira ${ }^{1}$, \\ Clayton Quirino Mendes ${ }^{1}$, Gerson Barreto Mourão ${ }^{2}$
}

\author{
1 Programa de Pós-graduação em Ciência Animal e Pastagens - ESALQ/USP - Piracicaba, SP. \\ 2 Departamento de Zootecnia, ESALQ - USP, Av. Pádua Dias no 11, Caixa Postal 9, CEP: 13418-900, Piracicaba, SP.
}

RESUMO - Objetivou-se avaliar o efeito de características físicas (densidade, solubilidade, tamanho médio de partículas e capacidade de retenção de água) sobre a fração efetivamente degradada in situ da matéria seca dos farelos de soja, canola, amendoim e algodão. Avaliou-se também a taxa de passagem de sólidos utilizando-se quatro ovinos castrados da raça Santa Inês canulados no rúmen. Amostras de $100 \mathrm{~g}$ de cada farelo proteico marcado com dicromato de sódio foram introduzidas no rúmen, e mantidas durante seis tempos de incubação $(0,3,6,12,24$ e 48 horas.) Os tempos de colheita de fezes foram de 0 , $9,12,24,36,48,72$ e 96 horas. Os parâmetros de solubilidade e capacidade de retenção de água modificaram a fração efetivamente degradada. A menor densidade e a maior proporção de parede celular do farelo de canola proporcionaram menor taxa de passagem dessa fonte proteica. Somente a capacidade de retenção de água influenciou a taxa de passagem de sólidos dos ingredientes avaliados. A solubilidade, a capacidade de retenção de água, o tamanho médio de partículas e a densidade devem ser utilizados na avaliação de alimentos para estudos de degradação e cinética ruminal. A introdução de novas características físicas na biblioteca de ingredientes de sistemas de avaliação de alimentos pode auxiliar na interpretação e na predição de parâmetros metabólicos.

Palavras-chave: capacidade de retenção de água, farelo de amendoim, farelo de canola, ovinos, tamanho médio de partículas

\section{Physical-chemical characteristics of protein sources and their interactions on ruminal degradation and passage rate}

\begin{abstract}
It was aimed to evaluate in this work the effects of physical characteristics (density, solubility, average particle size and water holding capacity) on in situ effective degraded fraction of the dry matter of soybean meal, canola meal, peanut meal, and cottonseed meal. It was also evaluated the passage rate of solids using four Santa Ines castrated wethers cannulated in the rumen. Samples with $100 \mathrm{~g}$ of each protein meal marked with sodium dichromate were put in the rumen and kept in there during six times of incubation $(0,3,6,12,24$, and 48 hours). Fecal collection times were $0,9,12,24,36,48$, 72 and 96 hours. Parameters of solubility and water holding capacity changed the effectively degraded fraction. The lowest density and the highest proportion of the cellular wall of canola meal provided the lowest passage rate of this protein source. Only water holding capacity influenced solid passage rate of the evaluated ingredients. The solubility, water holding capacity, average particle size and density should be used in the diet feed evaluation for degradation and ruminal metabolism studies. Introduction of new physical characteristics in the ingredient library of food evaluation system may help to interpret and to predict metabolic parameters.
\end{abstract}

Key Words: average particle size, canola meal, peanut meal, sheep, water holding capacity

\section{Introdução}

Os ruminantes são capazes de aproveitar volumosos de baixa qualidade de maneira eficiente, em virtude da síntese e da secreção de enzimas pelos microrganismos do rúmen. Entretanto, com a finalidade de aumentar a eficiência de ganho e reduzir o período de engorda dos animais, têm-se intensificado os sistemas de produção, nos quais são fornecidas rações com altas proporções de concentrado. $\mathrm{O}$ amido constitui a principal fonte de carboidratos nãofibrosos dessas rações, sendo sua capacidade de retenção de água limitada em 30\% do seu peso em água. O principal componente com essa característica é a pectina, que retém até $145 \%$ do seu peso em água (Ciacco \& Cruz, 1982). Outro fator determinante da capacidade de retenção de água são os parâmetros físicos. Segundo Seoane et al. (1981), 
alimento com baixa densidade apresenta bolsas de ar entre a matriz da parede celular, as quais podem reter água livre no ambiente ruminal.

A capacidade de retenção de água tem forte impacto na colonização pelos microrganismos (Bennink et al., 1978) e pode influenciar o efeito de enchimento, alterando a taxa de passagem (Ehle, 1984), enquanto o tamanho médio de partículas pode influenciar a área de superfície disponível ao ataque dos microrganismos (Owens \& Goetsch, 1988; Pereira et al., 2009). A principal característica física que contempla a biblioteca de ingredientes dos sistemas de avaliação de alimentos é o tamanho médio de partículas associado ao teor de fibra em detergente neutro (Mertens, 1997).

Tradicionalmente, o farelo de soja tem sido utilizado como suplemento proteico em rações para ruminantes. No entanto, pesquisas com fontes proteicas alternativas devem ser realizadas, principalmente quanto à composição química e às respostas metabólicas dessas fontes na produção animal. Contudo, nem sempre a composição química tem fornecido informações concretas sob o valor nutritivo dos alimentos, sendo pouco exploradas as análises físicas dos ingredientes, bem como as possíveis interações destas na degradação da matéria seca e na taxa de passagem pelo trato digestório total.

Objetivou-se com este estudo avaliar a influência das características físicas (densidade, solubilidade, capacidade de retenção de água e tamanho médio de partícula) sobre aspectos de degradação e passagem de fontes proteicas inclusas em dietas para ovinos contendo alta proporção de concentrado.

\section{Material e Métodos}

O experimento foi conduzido nas instalações do Sistema Intensivo de Produção de Ovinos e Caprinos do Departamento de Zootecnia, da Escola Superior de Agricultura "Luiz de Queiroz" da Universidade de São Paulo. Quatro borregos castrados da raça Santa Inês com peso corporal médio inicial de $48,0 \pm 5 \mathrm{~kg}$ e fistulados no rúmen foram utilizados. Os animais foram alojados individualmente em gaiolas metálicas para ensaios de metabolismo, providas de cocho e bebedouro, alimentados à vontade duas vezes por dia $(7 \mathrm{~h}$ e $17 \mathrm{~h})$, sendo as sobras pesadas diariamente. A coleta de fezes foi realizada utilizando-se sacolas de coleta total de fezes fixadas na porção posterior dos animais com o objetivo de reduzir a contaminação por pelos e urina.

As dietas foram isonitrogenadas $(16 \%$ de PB) formuladas pelo sistema Small Ruminant Nutrition System (SRNS) versão 1.8.1 (Cannas et al., 2004) e continham $10 \%$ de feno de Coastcross e $90 \%$ de concentrado, diferindo quanto à fonte suplementar de proteína: farelo de soja, farelo de amendoim, farelo de canola ou farelo de algodão (Tabela 1).

A cada período experimental, os animais foram submetidos a 10 dias de adaptação às gaiolas, às rações e

Tabela 1 - Proporção dos ingredientes e composição nutricional das dietas experimentais

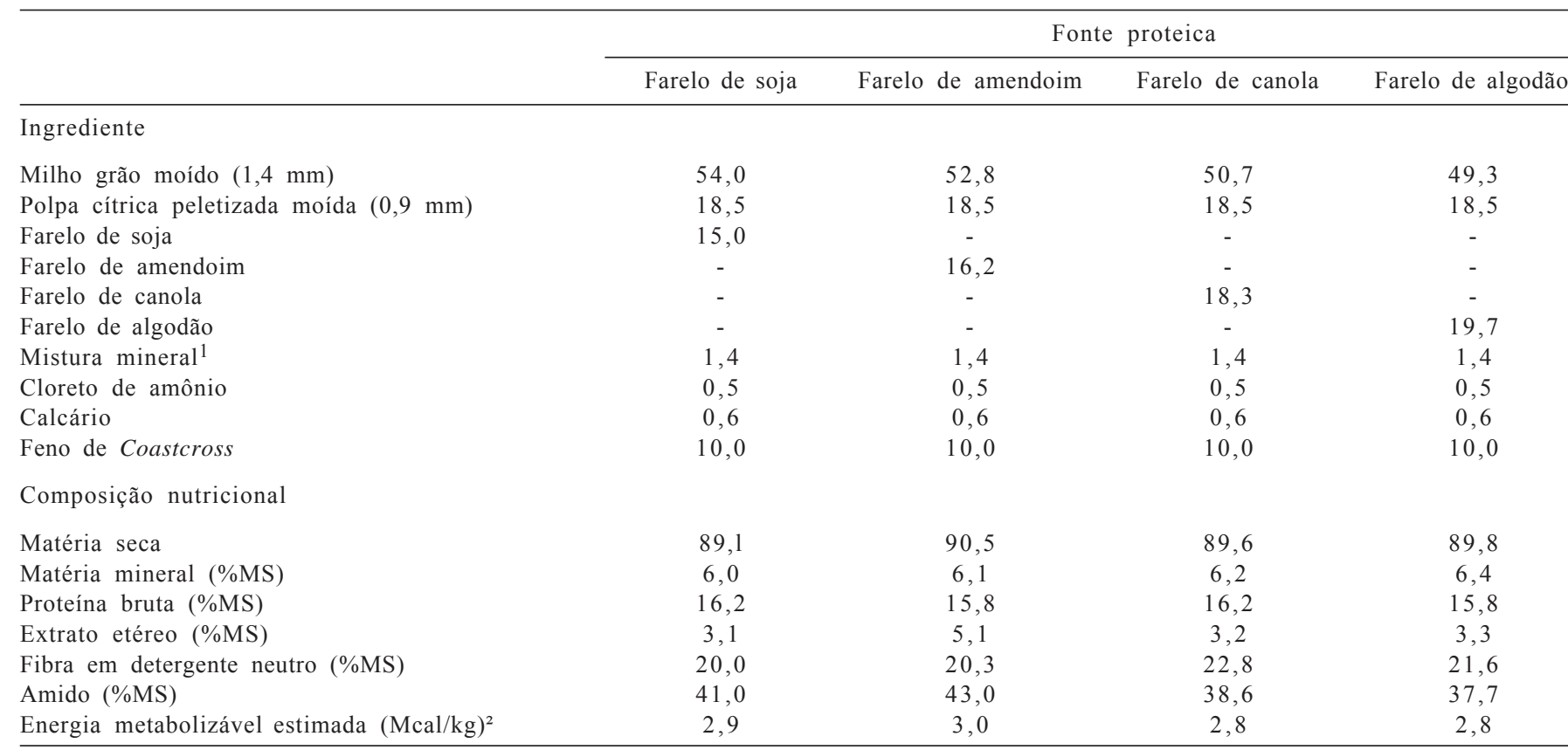

${ }^{1}$ Composição: fósforo - 7,5\%; cálcio - 19\%; magnésio - 1\%; enxofre - 7\%; sódio - 14,3\%; cloro - 21,8\%; ferro - 500 ppm; cobre - 300 ppm; zinco - 4.600 ppm; manganês $1.100 \mathrm{ppm}$; iodo - $80 \mathrm{ppm}$; cobalto - $405 \mathrm{ppm}$; selênio - $30 \mathrm{ppm}$. ${ }^{2}$ Determinada de acordo com o SRNS (Small Ruminant Nutrition System) 
às sacolas coletoras de fezes e cinco dias para colheita de amostras de fezes, para o ensaio de taxa de passagem. Além disso, foram utilizados mais três dias de incubação, para a determinação da fração efetivamente degradada, correspondendo período experimental total de 18 dias.

As fontes proteicas foram acondicionadas em sacos de náilon com porosidade de $50 \mu \mathrm{m}$ e dimensão de $7 \times 10 \mathrm{~cm}$, com tamanho de partícula original, sem processamento, contendo aproximadamente $3 \mathrm{~g}$ de MS. Essa quantidade de amostra resultou na relação de $20 \mathrm{mg}$ de MS por $\mathrm{cm}^{2} \mathrm{de}$ tecido, conforme proposto por Nocek (1988). Os tempos de incubação ruminal foram de $0,3,6,12,24$ e 48 horas, em seis repetições por horário, sendo as amostras introduzidas no rúmen em ordem cronológica reversa e retirada simultânea do material incubado.

Os sacos de náilon foram lavados em máquina tipo "tanquinho" durante 30 minutos, em três lavagens de 10 minutos e, posteriormente, submetidos à secagem em estufa com ventilação forçada a $65^{\circ} \mathrm{C}$, por 72 horas. Os resíduos foram analisados quanto aos teores de MS segundo AOAC (1990). Os dados de desaparecimento foram ajustados por regressão não linear, com técnica de otimização Dual Quasi-Newton, por intermédio do modelo proposto por Mehrez \& Orskov (1977): $\mathrm{p}=\mathrm{a}+\mathrm{b}\left(1-\mathrm{e}^{-\mathrm{kd} t}\right)$, em que $\mathrm{p}=$ fração degradada no tempo $\mathrm{t}(\%) ; \mathrm{a}=$ fração solúvel (\%); $\mathrm{b}=$ fração insolúvel potencialmente degradável $(\%) ; \mathrm{kd}=$ taxa de degradação da fração $\mathrm{b}\left(\mathrm{h}^{-1}\right) ; \mathrm{e} t=$ tempo de incubação (horas).

A fração efetivamente degradada (DE) foi calculada segundo o modelo matemático proposto por Orskov \& McDonald (1979): $\mathrm{DE}=\mathrm{a}+((\mathrm{b} \times \mathrm{kd}) /(\mathrm{kd}+\mathrm{kp}))$ em que $\mathrm{kp}$ equivale à taxa estimada de passagem de sólidos no rúmen por hora $\left(\mathrm{h}^{-1}\right)$ de cada fonte proteica. A fração solúvel (a) foi obtida pela lavagem com água em temperatura ambiente, em máquina tipo "tanquinho", duas vezes por 10 minutos sem incubação ruminal prévia. A fração indegradável (c) foi obtida pela equação: $\mathrm{c}=100-(\mathrm{a}+\mathrm{b})$.

A taxa de passagem da fase sólida foi mensurada para cada fonte proteica pelo uso do cromo mordente (Uden et al., 1980). A cada período experimental, foi introduzido no rúmen, conforme o respectivo tratamento, $100 \mathrm{~g}$ de cada ingrediente protéico mordentado. Os horários de coleta das fezes foram de 9, 12, 24, 36, 48, 72 e 96 horas após a introdução no rúmen do ingrediente mordentado. As curvas da concentração fecal do indicador foram ajustadas em função do tempo transcorrido desde sua administração, visando à estimação dos parâmetros da dinâmica de trânsito das partículas no trato gastrointestinal.

Para a interpretação das curvas de excreção foi utilizado o modelo bicompartimental tempo-independente sugerido por Grovum \& Williams (1973): $\mathrm{Y}=\mathrm{A}\left[\mathrm{e}^{-\mathrm{k} 1 \times(\mathrm{t}-\mathrm{TT})}-\mathrm{e}^{-\mathrm{k} 2 \times}\right.$ (t-TT) $]$, para $\mathrm{t} \geq \mathrm{TT}$ e $\mathrm{Y}=0$, para $\mathrm{t}<\mathrm{TT}$, em que Aé indefinido do ponto de vista biológico; $\mathrm{k}_{1}$ e $\mathrm{k}_{2}=$ taxas de passagem no rúmen-retículo e no ceco e cólon proximal, respectivamente; $\mathrm{TT}=$ tempo transcorrido entre o fornecimento e o aparecimento do indicador nas fezes; e $\mathrm{t}=$ tempo pósaplicação do indicador.

A densidade Bulk das fontes proteicas foi estimada em laboratório com proveta graduada Pyrex de $100 \mathrm{~mL}$, com 2,7 cm de diâmetro interno, por agitação manual, segundo Montgomery e Baumgardt (1965). O volume da proveta foi completado com amostra até a marca de $50 \mathrm{~mL}$ e agitada no sentido vertical por 15 segundos, sendo o peso e o volume (proveta + amostra) anotados. Em seguida, adicionou-se mais amostra na proveta até a marca de $100 \mathrm{~mL}$ e agitou-se por 10 segundos. Caso a amostra estivesse abaixo da marca de $100 \mathrm{~mL}$, a proveta era completada na marca de $100 \mathrm{~mL}$ e agitava-se por 5 segundos. E, por fim, o peso total e o volume final foram registrados.

O tamanho médio de partícula (TMP) dos farelos proteicos foi estimado utilizando-se agitador automático e peneiras, com crivos de 4,00, 2,00, 1,00, 0,84; 0,42 e $0,25 \mathrm{~mm}$, conforme técnica descrita por Yu et al. (1998). Inicialmente, foram registradas as taras de todas as peneiras e, posteriormente, pesados $250 \mathrm{~g}$ de amostra. A amostra foi colocada sob a primeira peneira $(4,00 \mathrm{~mm}) \mathrm{e}$ agitada na posição horizontal em agitador automático por quatro minutos na potência oito da escala 1 a 10 do equipamento (Marca Telastem Modelo Produtest $n^{\circ} 705$ ). Finalizado esse procedimento, as peneiras e suas amostras retidas foram pesadas para efeito de cálculo do TMP de cada ingrediente.

A média do tamanho de partículas foi calculada, assumindo-se que o ingrediente retido na peneira de 4,00 $\mathrm{mm}$ tem o tamanho de partícula médio de $6,00 \mathrm{~mm}, \mathrm{o}$ qual foi multiplicado pela porcentagem retida na peneira 4,00 $\mathrm{mm}$. Esse valor foi somado ao resultado das médias entre as peneiras maiores e menores, vezes o percentual retido na peneira menor (exemplo: $4,00 \mathrm{~mm}+2,00 \mathrm{~mm} \div 2=3$, que, multiplicado por gramas de amostra retida $=\mathrm{TMP}, \mathrm{e}$ assim sucessivamente). As partículas que passaram pela peneira de crivo $0,25 \mathrm{~mm}$ foram consideradas como tendo $0,12 \mathrm{~mm}$.

A capacidade de retenção de água foi mensurada usando algumas modificações do método de Robertson \& Eastwood (1981), sendo utilizada a amostra intacta em invés da porção fibrosa. Amostras dos farelos contendo $2,5 \mathrm{~g}$ foram embebidas por $16-24$ horas em $250 \mathrm{~mL}$ de água destilada em Becker de $500 \mathrm{~mL}$ e, posteriormente, filtradas sem vácuo em cadinho de placa porosa. A amostra úmida 
foi pesada após 10 minutos em que ficou decantando. A capacidade de retenção de água foi a quantidade de água retida na amostra, e expressa em $1 \mathrm{~kg}$ de amostra seca.

A amostra filtrada coletada depois da passagem no cadinho de placa porosa foi seca em estufa $\left(100^{\circ} \mathrm{C} / 72\right.$ horas). A matéria seca solubilizada foi expressa $\mathrm{em}^{-1}{ }^{-1} \mathrm{ou}$ sob a porcentagem do peso inicial do ingrediente estudado. Todas as análises físicas foram realizadas com quatro repetições por amostra.

Os teores de matéria seca (MS), matéria mineral (MM), extrato etéreo (EE) e proteína bruta $(\mathrm{PB})$ das fontes proteicas foram determinados segundo AOAC (1990). A análise de fibra em detergente ácido foi realizada segundo Van Soest (1967) e a fibra em detergente neutro, de acordo com Van Soest et al. (1991). As análises de amido foram feitas conforme Poore et al. (1989) por intermédio de hidrólise enzimática do amido da amostra e determinação da glicose resultante. Os teores de pectina foram estimados conforme Gorshkova et al. (1996) baseando-se no isolamento de parede celular, segundo Fukushima \& Hatfield (2001).

O delineamento experimental foi em quadrado latino $4 \times 4$ em estrutura de medidas repetidas no tempo contemplando 96 observações $(16 \times$ seis horários de incubação) no estudo de degradação e 112 observações ( $16 \times$ sete horários de coleta de fezes) no estudo de trânsito de alimentos. Os parâmetros de degradação e trânsito ruminal foram analisados sob modelo misto para cada tratamento em função do tempo, com uso do procedimento NLMIXED do programa Statistical Analysis System (SAS, 2003) e análise de regressão múltipla entre os parâmetros físicos e a degradação e trânsito ruminal pelo PROC REG (SAS, 2003), adotando-se $\mathrm{P}<0,05$.

\section{Resultados e Discussão}

O farelo de soja e o farelo de amendoim apresentaram teores médios de 7,5 e 7,8\% de pectina na matéria seca e o farelo de canola e o farelo de algodão, os teores médios de 2,9 e $5,8 \%$, respectivamente. O principal modulador do teor de pectina em diferentes lotes de farelo de soja é a concentração da casca de soja separada no processamento do grão de soja e devolvida ao farelo. Contudo, além da alta proporção de proteína (52\%) do farelo de soja, este apresentou significativa concentração de fibra solúvel (pectina). Os valores de pectina no farelo de soja (Tabela 2) foram semelhantes aos obtidos por Honig \& Rackis (1979).

A densidade Bulk foi negativamente correlacionada com a fibra em detergente neutro (FDN) dos farelos proteicos como observado na equação 1 , de modo que, quanto maior o teor de FDN, menor a densidade do alimento e menor a solubilidade, como observado por GigerReverdin (2000).

$$
\begin{aligned}
& \text { Den }=0,774-0,483 \times \text { FDN }(g / k g M S) \\
& \left(r^{2}=0,594 ; \mathrm{n}=16\right)
\end{aligned}
$$

A fonte proteica com maior capacidade de retenção de água foi o farelo de canola, que não continha maior proporção de amido e pectina, porém apresentou numericamente menor densidade em relação às demais fontes proteicas (Tabela 2). Segundo Giger-Reverdin (2000), geralmente alimentos com alta capacidade de retenção de água apresentam menor densidade, uma vez que baixa densidade significa bolsas de ar entre os componentes da matriz orgânica da parede celular, as quais podem reter água quando em excesso no rúmen, tendo maior capacidade de enchimento e menor taxa de trânsito, porém maior tempo

\begin{tabular}{|c|c|c|c|c|}
\hline & \multicolumn{4}{|c|}{ Fonte proteica } \\
\hline \multicolumn{5}{|l|}{ Composição nutricional } \\
\hline Matéria seca, \% & 90,0 & 96,0 & 90,4 & 92,0 \\
\hline Matéria mineral, \% MS & 6,7 & 6,0 & 6,2 & 6,6 \\
\hline Proteína bruta, \% MS & 52,0 & 49,2 & 44,5 & 42,0 \\
\hline Extrato etéreo, \% MS & 0,6 & 14,2 & 2,3 & 2,4 \\
\hline Fibra detergente ácido, \% MS & 10,0 & 10,2 & 19,4 & 18,5 \\
\hline Hemicelulose, \% MS & 1,7 & 4,0 & 8,6 & 4,0 \\
\hline Amido, \% MS & 3,9 & 11,4 & 4,3 & 1,6 \\
\hline Pectina, \% MS & 7,5 & 7,8 & 2,9 & 5,8 \\
\hline \multicolumn{5}{|l|}{ Características físicas } \\
\hline
\end{tabular}

Tabela 2 - Composição nutricional e características físicas das fontes proteicas 
Tabela 3 - Tamanho de partículas das fontes proteicas (\% retida nas peneiras)

\begin{tabular}{lcccc}
\hline & \multicolumn{3}{c}{ Fonte proteica } \\
\cline { 2 - 5 } Diâmetro da peneira & Farelo de soja & Farelo de amendoim & Farelo de canola & Farelo de algodão \\
\hline $2,00 \mathrm{~mm}$ & 4,4 & 23,8 & 1,9 & 7,5 \\
$1,00 \mathrm{~mm}$ & 51,2 & 29,7 & 13,5 & 3,7 \\
$0,84 \mathrm{~mm}$ & 15,2 & 7,1 & 46,4 & 10,5 \\
$0,42 \mathrm{~mm}$ & 22,7 & 37,7 & 16,1 & 1,4 \\
$0,25 \mathrm{~mm}$ & 3,8 & 0,5 & 13,4 & 8,2 \\
$<0,25 \mathrm{~mm}$ & 2,7 & 1,2 & & 8,5 \\
\hline
\end{tabular}

para a ação das enzimas dos microrganismos e, consequentemente, maior degradação.

Nesse contexto, entre as características químicas e físicas associadas à capacidade de retenção de água, o principal influenciador dessa variável foi a densidade dos alimentos, mesmo reconhecendo o alto poder de retenção de água da pectina.

Em complementação ao estudo do tamanho médio de partículas, na Tabela 3 encontra-se a distribuição do tamanho de partículas nas diferentes peneiras, para auxiliar as possíveis perdas por lavagem na avaliação da fração solúvel no estudo da degradabilidade in situ (Tabela 4).

Entre as características físicas avaliadas, dados de pesquisa permitem evidenciar, além da solubilidade, grande participação do tamanho médio de partículas na determinação dessa fração em estudos de degradação de alimentos no rúmen (Ezequiel \& Galati, 2007). Entretanto, o tamanho médio de partículas foi de 1,2;1,5;0,7 e 1,1 mm para os ingredientes farelos de soja, amendoim, canola e algodão, respectivamente (Tabela 2). Considerando a porosidade da malha utilizada no ensaio de degradação $(50 \mu \mathrm{m})$ e observando o somatório das porcentagens de partículas retidas nas peneiras $0,42,0,25$ e menor que $0,25 \mathrm{~mm}$ (Tabela 3), os farelos deveriam apresentar solubilidade esperadas de 29,2;39,4; 75,8 e 43,0\% para farelos de soja, amendoim, canola e algodão, respectivamente. Contudo, esse comportamento não foi observado, uma vez que a solubilidade encontrada foi de 29,$3 ; 41,5 ; 27,5$ e $25,8 \%$ para farelos de soja, amendoim, canola e algodão, respectivamente (Tabela 4). Provavelmente, essas diferenças podem estar alicerçadas nas particularidades de hidratação da amostra mensurada pela capacidade de retenção de líquidos que poderão vir a influenciar a solubilidade de nutrientes no rúmen.

O farelo de canola apresentou menor tamanho médio de partículas e maior porcentagem de partículas inferiores a $0,84 \mathrm{~mm}$, o que não refletiu em maior fração prontamente solúvel. Tais valores são coerentes quando analisado o parâmetro físico de solubilidade da MS, cujos valores foram de 21,$0 ; 20,0 ; 17,6$ e 16,4\% para farelos de soja, amendoim, canola e algodão, respectivamente (Tabela 2).

A fonte proteica que apresentou maior fração solúvel foi o farelo de amendoim (Tabela 4). Como os ingredientes proteicos foram incubados no seu tamanho de partícula original sem o processamento de moagem, a explicação mais plausível para a menor solubilidade do farelo de canola pode ser devido à maior capacidade de retenção de água de 4,1 $\mathrm{L} \mathrm{kg}^{-1}$ MS em relação a 3,7 $\mathrm{L} \mathrm{kg}^{-1}$ MS do farelo de amendoim (Tabela 2). A maior capacidade de retenção de água amenizou a perda de partículas pela porosidade da malha com a lavagem.

A superestimação da fração solúvel (a) reduz a estimativa da fração insolúvel potencialmente degradável (b) e amplia a estimativa da fração efetivamente degradada. Segundo Ezequiel \& Galati (2007), a solubilidade determinada em ensaios de degradabilidade utilizando líquido ruminal em

Tabela 4 - Solubilidade e taxa de degradação da MS das fontes proteicas

\begin{tabular}{|c|c|c|c|c|}
\hline Parâmetro & \multicolumn{4}{|c|}{ Fonte proteica } \\
\hline Fração solúvel $(\%)$ & $29,3(1,74)^{1}$ & $41,5(1,74)$ & $27,5(1,74)$ & $25,8(1,49)$ \\
\hline Fração indegradável $(\%)$ & $8,6(4,02)$ & $3,2(2,15)$ & $27,0(2,02)$ & $36,7(1,84)$ \\
\hline Taxa de degradação (kd, \%/hora) & $3,9(0,53)$ & $6,2(0,60)$ & $7,1 \quad(0,84)$ & $8,2(1,15)$ \\
\hline Taxa de passagem $(\mathrm{kp}, \% /$ hora $)$ & $5,2(0,05)$ & $4,7(0,05)$ & $4,3 \quad(0,05)$ & $5,5(0,05)$ \\
\hline
\end{tabular}

\footnotetext{
${ }^{1}$ Erro-padrão da estimativa entre parênteses.
} 
máquinas tipo "tanquinho" é pelo menos $34 \%$ menor que aquela obtida em "tanquinho" com água, pois as propriedades físicos-quimicas do líquido ruminal são diferentes das propriedades da água. No presente estudo, os resultados de solubilidade em água obtidos no laboratório (Tabela 2) foram em média 37,2\% menores do que os valores obtidos por meio da máquina tipo "tanquinho" (Tabela 4). Com base nesses resultados e na afirmação de Ezequiel \& Galati (2007) supracitada, podemos inferir que a determinação da solubilidade em laboratório se aproxima mais dos valores obtidos a partir de material do rúmen, colocando-se como alternativa à coleta de líquido ruminal para a estimativa da fração solúvel, considerando a quantidade de líquido ruminal utilizada e a necessidade de animais fistulados.

Os valores da fração indegradável (c) foram aproximadamente $38,9 \%$ maiores para o farelo de canola e farelo de algodão em relação ao farelo de soja e ao farelo de amendoim. Tal resultado pode ser explicado pela proporção de fibra em detergente ácido (19\%) encontrada nesses farelos em relação às presentes nos farelos de soja e amendoim (10\%).

A fração efetivamente degradada apresentou valor superior para o farelo de amendoim em 32,9\% em relação aos demais farelos proteicos. A composição química desse alimento apresenta menores teores de fibra em detergente neutro e fibra em detergente ácido e maiores teores de proteína bruta e amido (Tabela 2), ou seja, menor teor de parede celular, notoriamente de maior velocidade de degradação ruminal. A concentração de $14 \%$ de lipídeos no farelo de amendoim parece não ter comprometido a fração efetivamente degradada da matéria seca, que foi $70,7 \%$ superior aos farelos de canola, soja e algodão $(56,5 ; 53,3$ e $49,8 \%$ ), respectivamente.

De acordo com os resultados da análise de regressão múltipla, observou-se que os três parâmetros físicos (densidade, solubilidade e tamanho médio de partículas) explicaram aproximadamente $91 \%$ da interação desses parâmetros com a degradabilidade, como representado pela seguinte equação: $\mathrm{DE}=212,65-377,96 \times($ Den $)+1,43 \times$
$($ Solub $)+67,96 \times($ TMP $)$

$\left(\mathrm{r}^{2}=0,915\right)$

Pode-se inferir pela análise dos dados das características físicas que, quanto maior a solubilidade e a capacidade de retenção de água, maior a fração efetivamente degradadada da matéria seca das fontes proteicas (Tabelas 2 e 4). Alimentos que oferecem maior solubilidade da matéria seca concomitantemente dispõem de maior fração potencialmente degradável e menor fração indegradável (Tabela 4).

A taxa de passagem do material particulado do rúmen $\left(\mathrm{k}_{1}\right)$ foi aproximadamente de $13 \%$ a $32 \%$ menor $(\mathrm{P}<0,05)$ para a ração contendo o farelo de canola em relação às demais rações (Tabela 5). Ao analisar a densidade das fontes proteicas (Tabela 2), verifica-se que os farelos de soja, amendoim e algodão apresentaram maior densidade em relação ao farelo de canola e, simultaneamente, maior taxa de passagem $\left(\mathrm{k}_{1}\right)$.

Em média, alimentos com baixa densidade apresentam alto conteúdo de fibra em detergente neutro, como observado para o farelo de canola (Tabela 2), proporcionando maior efeito de enchimento no rúmen do que alimentos com alta densidade. Esse comportamento corrobora com as observações de Sing \& Narang (1991) ao avaliarem algumas forragens. Poucos são os trabalhos que relacionam esse parâmetro físico com a taxa de passagem de subprodutos ou concentrado. Segundo vários autores, a densidade apresenta grande importância e influência no trânsito da digesta no rúmen e, consequentemente, na ingestão de matéria seca (Montgomery \& Baumgardt, 1965; Ehle, 1984).

O momento em que as primeiras moléculas do elemento cromo saíram nas fezes corresponde ao tempo de trânsito, o qual foi inferior a dez horas após a introdução do marcador com maior velocidade de escape para as rações contendo o farelo de soja ou farelo de amendoim em relação às rações com farelo de canola ou farelo de algodão (Tabela 5). O tempo médio de retenção dos pools 1 e 2 corresponde o comportamento inverso ao do $\mathrm{k}$, em que os tratamentos

Tabela 5 - Taxa de passagem de sólidos da digesta de ovinos alimentados com diferentes fontes proteicas

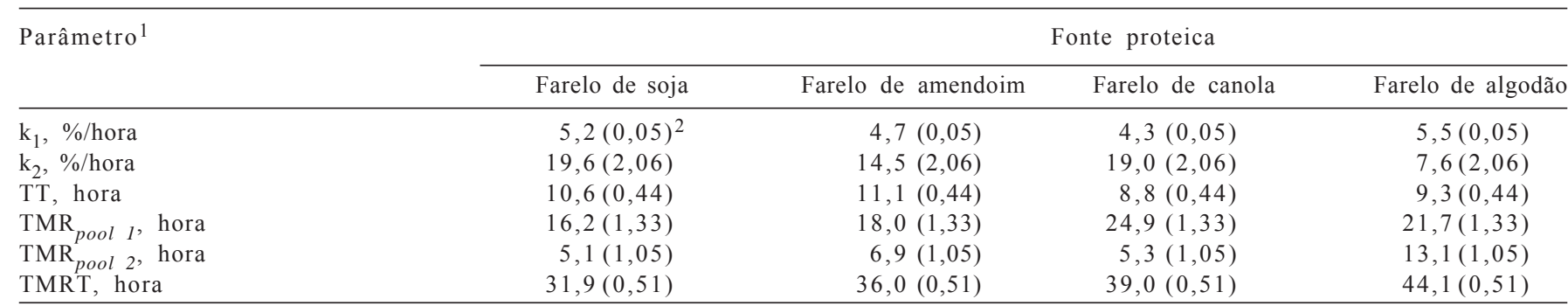

${ }^{1}$ Parâmetro: k1 e k2 = taxa de trânsito pelos pools 1 e 2; TT = tempo de trânsito; TMRpool 1 e TMRpool 2 = tempo médio de retenção nos pools 1 e 2; TMRT = tempo médio de retenção total.

${ }^{2}$ Erro-padrão da estimativa entre parênteses. 
com maior taxa de passagem $\left(\mathrm{k}_{1}\right)$ exibiram menor tempo médio de retenção. Bürger et al. (2000), ao estimarem a taxa de passagem do farelo de soja em bezerros alimentados com $90 \%$ de concentrado, encontraram tempo médio de retenção dos dois pools ou compartimentos de aproximadamente 30 horas, valor próximo ao observado no presente estudo, que foi em média 38 horas.

De acordo com a análise de regressão múltipla que contemplou as três variáveis físicas (densidade, solubilidade, tamanho médio de partículas), foi possível observar que há $56 \%$ da interação desses parâmetros com a taxa de passagem, como representado pela seguinte equação:

$$
\mathrm{k}_{1}=0,186-0,208 \times(\text { Den })-0,001 \times(\text { Solub })+0,033 \times
$$

$\left(\mathrm{r}^{2}=0,563\right)$

Pode-se inferir pela análise dos dados das características físicas que alimentos como o farelo de amendoim, quanto maior a solubilidade, menor a taxa de passagem das fontes proteicas (Tabelas $2 \mathrm{e} 5$ ). Alimentos ricos em pectina, como a polpa cítrica, apresentam alta solubilidade. Entretanto, rações com altos teores desse subproduto limitam o consumo da matéria seca devido a fatores quimiotáticos ou de efetividade física do alimento, causando enchimento ou saciedade aos ruminantes (Pereira et al., 2007; Rodrigues et al., 2008). Entretanto, esse mesmo comportamento não foi observado com o farelo de soja, que, apesar de ter apresentado proporção de pectina semelhante à do farelo de amendoim (Tabela 2), não mostrou menor taxa de passagem (Tabela 5). Dessa forma, ressalta-se a necessidade de mais pesquisas sobre os efeitos das características físico-químicas na taxa de passagem.

O tamanho médio de partícula tem baixa correlação com a densidade dos alimentos devido à heterogeneidade dos mesmos (Giger-Reverdin, 2000). Adicionalmente, Maaroufi et al. (1999) não encontraram qualquer correlação significativa entre esses parâmetros físicos. Teoricamente, alimentos com menor tamanho de partículas apresentam maior densidade. Contudo, existem particularidades conforme observado neste estudo para o farelo de canola (Tabela 2).

\section{Conclusões}

Os parâmetros da degradação e passagem ruminal são influenciados pelas características físicas dos alimentos, que são interdependentes, e estes efeitos são mais proeminentes na fração efetivamente degradável. A solubilidade, a capacidade de retenção de água, o tamanho médio de partículas e a densidade devem ser utilizados na avaliação de alimentos para estudos de degradação e cinética ruminal dos ingredientes de uma dieta.
A introdução de novas características físicas na biblioteca de ingredientes de sistemas de avaliação de alimentos pode auxiliar na interpretação e na predição de parâmetros metabólicos.

\section{Referências}

ASSOCIATION OF OFFICIAL ANALYTICAL CHEMISTIS AOAC. Official methods of analysis. 11.ed. Washington D.C., 1990. p.1051.

BENNINK, M.R.; TYLER, T.R.; WARD, G.M. et al. Ionic milieu of bovine and ovine rumen as affected by diet. Journal of Dairy Science, v.61, p.315-323, 1978 .

BÜRGER, P.J.; PEREIRA, J.C.; COELHO DA SILVA, J.F.C. et al. Taxas de passagem e cinética da degradação ruminal em bezerros holandeses alimentados com rações contendo diferentes níveis de concentrado. Revista Brasileira de Zootecnia, v.29, n.1, p.225-235, 2000.

CANNAS, A.; TEDESCHI, L.O.; FOX, D.G. et al. A mechanistic model for predicting the nutrient requirements and feed biological value for sheep. Journal of Animal Science, v.82, p.149-169, 2004.

CIACCO, C.F.; CRUZ, R. Fabricação de amido e sua utilização. São Paulo: Secretaria da Indústria, Comércio, Ciência e Tecnologia, 1982. 152p. (Série Tecnológica Agroindustrial).

EHLE, F.R. Influence of feed particle density on particulate passage from rumen of holstein cow. Journal of Dairy Science, v.67, p.693-697, 1984.

EZEQUIEL, J.M.B., GALATI, R.L. Técnicas in vitro e in situ para estimativa da digestibilidade ruminal de alimentos. In: SIMPÓSIO INTERNACIONAL EM AVANÇOS EM TÉCNICAS DE PESQUisA EM NUTRIÇÃO DE RUMINANTES, Pirassununga. Anais... Pirassununga, 2007. p.16-71.

FUKUSHIMA, R.S.; HATFIELD, R.D. Extraction and isolation of lignin and its utilization as standard to determine lignin concentration through a spectrophotometer method. Journal of Agricultural and Food Chemistry, v.49, n.7, p.3133-3139, 2001.

GIGER-REVERDIN，S. Characterisation of feedstuffs for ruminants using some physical parameters. Animal Feed Science and Techonology, v.86, p.53-69, 2000.

GORSHKOVA, T.A.; WYATT, S.E.; SALINIKOV, V.V. et al. Cellwall polysaccharides of developing flax plants. Physiology, v.110, p.721-729, 1996.

GROVUM, W. L.; WILLIAMS, V.J. Rate of passage of digesta in sheep. 4. Passage of marker through the alimentary tract and the biological relevance of rate-constants derived from the changes in concentration of marker in feces. British Journal of Nutrition, v.30, p.313-329, 1973.

HONIG, D.H.; RACKIS, J.J. Determination of the total pepsin pancreatin indigestible content (dietary fiber) of soybean products, wheat bran, and corn bran. Journal of Agricultural and Food Chemistry, v.27, p.1262-1266, 1979.

MAAROUFI, C.; MELCION, J.P.; DE MONREDON, F. et al. Fractionation of pea flour with pilot scale sieving. I. Physical and chemical characteristics of pea seed fractions. Animal Feed Science and Technology, v.85, p.61-78, 1999.

MEHREZ, A.Z.; ORSKOV, E.R.; McDONALD, I. Rates of rumen fermentation in relation to ammonia concentration. British Journal of Nutrition, v.38, n.3, p.437-443, 1977.

MERTENS, D.R. Creating a System for meeting the fiber requirements of dairy cows. Journal of Dairy Science, v.80, p.1463-1481, 1997.

MONTGOMERY, M.J; BAUMGARDT, B.R. Regulation of food intake in ruminants.2. Rations varying in energy concentration and physical form. Journal of Dairy science, v.48, p.1623-1628, 1965. 
NOCEK, J.E. In situ and other methods to estimate ruminal protein and energy digestibility: a review. Journal of Dairy Science, v.71, p.2051-2069, 1988 .

ORSKOV, E.R.; McDONALD, I. The estimation of protein degradability in the rumen from incubation measurement weighted according to rate of passage. Journal of Agricultural Science, v.92, n.1, p.499-503, 1979.

OWENS, F.N.; GOETSCH, A.L. Digesta passage and microbial protein synthesis. In: MILLIGAN, L.P.; GROVUM, W.L.; DOBSON, A. (Eds.) Control of digestion and metabolism in ruminants. Englewood Cliffs: Prentice Hall, 1988. p.196-223.

PEREIRA, E.M.; SANTOS, F.A.P.S.; NUSSIO, L.G. et al. Estimativa de energia metabolizável de rações com polpa cítrica em substituição ao milho para tourinhos em terminação. Revista Brasileira de Zootecnia, v.36, p.216-224, 2007.

PEREIRA, E.S.; MIZUBUTI, I.Y.; RIBEIRO, E.L.A. et al. Consumo, digestibilidade aparente dos nutrientes e comportamento ingestivo de bovinos da raça Holandesa alimentados com dietas contendo feno de capim-tifton 85 com diversos tamanhos de partícula. Revista Brasileira de Zootecnia, v.38, n.1, p.190-195, 2009

POORE, M.H.; ECK, T.P.; SWINGLE, R.S. et al. Total starch and relative starch availability of feed grains. In: BIENNIAL CONFERENCE ON RUMEN FUNCTION, 20., 1989, Chicago. Proceedings.... Chicago, 1989. (CD-ROM).

ROBERTSON, J.A.; EASTWOOD, M.A. An investigation of the experimental conditions which could affect water-holding capacity of dietary fiber. Journal of the Science of Food and Agriculture, v.32, p.819-825, 1981.
RODRIGUES, G.H.; SUSIN, I., PIRES, A.V. et al. Substituição do milho por polpa cítrica em rações com alta proporção de concentrado para cordeiros confinados. Ciência Rural, v.38, n.3, p.789-794, 2008.

SEOANE, J.R.; COTE, M.; GERVAIS, P. Prediction on the nutritive value of alfalfa (Saranc), bromegrass (Saratoba) and timothy (Champ, Climax, Bounty) fed as hay to growing sheep. Canadian Journal of Animal Science, v.61, p.403-413, 1981.

SING, B.; NARANG, M.P. Some physic-chemical characteristics of forage and their relationships to digestibility. Indian Journal of Animal Nutrition, v.8, p.179-186, 1991.

STATISTICAL ANALYSIS SYSTEM - SAS. SAS/STAT: guide for personal computer. Version 9.1. Cary, 2003. 235p.

UDÉN, P.; COLUCCI, P.E.; VAN SOEST, P.J. Investigation of chromium, cerium and cobalt as markers in digesta. Rate of passage studies. Journal of the Science of Food and Agriculture, v.31, n.2, p.625-638, 1980.

VAN SOEST, P.J. Development of a comprehensive system of feed analysis and its application to forage. Journal of Animal Science, v.26, n.1, p.119-120, 1967.

VAN SOEST, P.J.; ROBERTSON, J.B.; LEWIS, B.A. Methods for dietary fiber, neutral detergent fiber, and nonstarch polysaccharides in relation to animal nutrition. Journal of Dairy Science, v.74, p.3583-3597, 1991.

YU, P.; HUBER, J.P., SANTOS F.A.P. et al. Effects of ground, steam-flaked, and steam-rolled corn grains on performance of lactating cows. Journal of Dairy Science, v.81, n.3, p.777-783, 1998 